\title{
The environmental health nexuses within the Strategic Roadmap: regional work priorities for the WHO Eastern Mediterranean Region
}

Ahmad Basel Al-Yousfi ${ }^{1}$, Hamed Bakir ${ }^{1}$ and Mazen Malkawi ${ }^{1}$

${ }^{1}$ World Health Organization, Regional Office for the Eastern Mediterranean, Centre for Environmental Health Action, Amman, Jordan

Citation: Al-Yousfi AB; Bakir H; Malkawi M. The environmental health nexuses within the strategic roadmap: regional work priorities for the WHO Eastern Mediterranean Region. East Mediterr Health J. 2018;24(2):117-118. https://doi.org/10.26719/2018.24.2.117.

Copyright (C) World Health Organization (WHO) 2018. Some rights reserved. This work is available under the CC BY-NC-SA 3.0 IGO license (https:// creativecommons.org/licenses/by-nc-sa/3.o/igo).

The Eastern Mediterranean Region (EMR) is a diverse region in terms of income, development, health and environmental conditions. The environment and ecosystems are under serious pressures with adverse impacts on human health and well-being. Environmental Health (EH) is an area of growing importance for EMR, and environmental risk factors such as air, water and soil pollution, chemical exposures, climate change and radiation, contribute to more than 100 diseases and injuries, and environmental hazards are responsible for about $22 \%$ of the total burden of disease in the Region (1).

The health impacts of environmental risks are manifested as both communicable and noncommunicable diseases in all EMR countries. It is estimated that more than 854000 people (including more than 210000 children aged less than 5 years) die prematurely every year as a result of living and/or working in unhealthy environments (nearly 1 in 5 of total regional deaths annually). Interestingly, over three quarters of these deaths are the result of noncommunicable diseases and injuries (2). Such burdens of diseases are further exacerbated by the combined effects of climate change, biodiversity loss and the degradation of natural systems.

About one half of the premature environmentally caused deaths are attributable to indoor and outdoor air pollution; the other half is due to chemical exposures, lack of or inadequate water and sanitation and hygiene (WSH) services, amongst other environmental hazards (3). Air pollution with particulate matter (PM) reached alarming levels in many cities of the Region and approximately $98 \%$ of the urban populations breathe air exceeding WHO safe levels by up to 12 fold, causing 400 ooo deaths annually (4).

The top 5 "environmental" causes of death in the Region are heart disease, stroke, unintentional injuries, respiratory infections and diarrheal diseases, which target the most vulnerable, i.e., children and the elderly (1). Climate change poses serious, but preventable, risks to public health. In the Region, climate change is producing more frequent and more intense heat waves, floods, droughts and dust storms. Its effects are being seen in increasing mortality and morbidity rates, including airborne respiratory diseases, water and food-borne diseases, vector-borne diseases, malnutrition, heat stress and occupational injuries (5).

Both man-made and natural emergencies have hit many EMR countries. The effects of environmental risks, accompanied by lack of environmental health services, on morbidity and mortality rates during crises are pronounced in the Region. Addressing the environmental health aspects of emergencies requires WHO to work with all countries to invest in vulnerability and risk assessment, preparedness, response and recovery planning.

Environmental risks are key determinants of health across the life course. Management of such risks to minimize related health effects is a multi-stakeholder mission needing adoption and implementation of an overarching integrated "ecological public health approach". This needs to recognize the complex interactions between biological, behavioural, environmental and social factors across the envisaged technical health priority areas in the Region.

The strategic vision for such a cross-cutting, multisectoral environmental health approach is delineated through the Framework for Action on Health and the Environment 2014-2019 (6), covering water, sanitation, waste, air quality, chemicals and climate change, as well as occupational health. This will be fortified by the regional food safety plan of action (2017-2022), strengthening food safety systems based on the "Fork to Plate" approach (7). Moreover the 2030 Agenda for Sustainable Development Goals (SDGs) is offering a new vehicle with emphasis on nexuses between developments, the environment, public health and human well-being

The nexus between health equity, socio-economic equality and environmental justice is well-evidenced in the public health arena. In order to address this mandate and undertake proper actions to mitigate the impact of environmental risks, mapping environmental health across the health priorities roadmap in the EMR (20172021) (8) is essential for overarching inter-linkages in terms of entry points, impacts, interventions and tools.

The health sector in the Region will need to assume the roles of stewarding broker and interlocutor in partnership with other pertinent actors. It is essential that a collaborative multi-agency approach is adopted, emphasizing the leadership of the public health sector in terms of governance and surveillance responsibilities, as well as advocacy and motivation of other specialized environmental health service agencies. This entails leveraging of environmental and social determinants 
of health (S\&EDH) by vertical programmes such as noncommunicable diseases, communicable diseases, maternal and child health, nutrition, emergencies etc.

WHO will continue to provide technical support to Member States for enhancing the capacity of the public health sector to evaluate, monitor, regulate and manage environmental risks. This includes strengthening the advocacy, partnership building and leadership roles of the health sector for mobilizing resources, and bringing synergy to the actions of pertinent sectors and of providers of environmental health services. In addition, WHO will equip the health sector with environmental norms and standards, guidelines and assessment tools in order to support stakeholders in integrating health protection measures into their development processes.

\section{References}

1. World Health Organization. Preventing disease through healthy environments: a global assessment of the burden of disease from environmental risks. Geneva: World Health Organization; 2016.

2. WHO Regional Office for the Eastern Mediterranean (EMRO). Plan of action for regional implementation of the global roadmap to address the health impacts of indoor and outdoor air pollution 2021-2017 EM/RC64. Cairo: EMRO; October 2017.

3. World Health Organization. Global Health Observatory (GHO). Geneva: World Health Organization; September 2017 (http:// www.who.int/gho/en/).

4. World Health Organization. Ambient air pollution: a global assessment of exposure and burden of disease. Geneva: World Health Organization; 2016 (http://apps.who.int/iris/bitstream/handle/-9789241511353/250141/10665eng.pdf;jsessionid=831D9D1CC1DE618 $527 \mathrm{C}_{51 D E} 45 \mathrm{E}_{1} \mathrm{CE} 4 \mathrm{Al}$ ?sequence $=1$ ).

5. WHO Regional Office for the Eastern Mediterranean (EMRO). Climate change and health: framework for action 2021-2017, EM/ RC4/64. Cairo: EMRO; October 2017 (http://applications.emro.who.int/docs/RC_technical_papers_20040_4_2017_en.pdf?ua=1).

6. WHO Regional Office for the Eastern Mediterranean (EMRO). Framework for action on health and the environment $2019-2014$. Cairo: EMRO; 2013 (http://applications.emro.who.int/docs/Framework_Action_EN.pdf?ua=1).

7. WHO Regional Office for the Eastern Mediterranean (EMRO). Expert consultation on the development of a plan of action for food safety in the Eastern Mediterranean Region 2022-2017. Cairo; EMRO; 2016 (http://applications.emro.who.int/docs/IC_Meet_ Rep_19173_2016_EN.pdf).

8. WHO Regional Office for the Eastern Mediterranean (EMRO). Roadmap of WHO's work for the Eastern Mediterranean Region 2021-2017. Cairo: EMRO; September 2017 (http://applications.emro.who.int/docs/EMROPUB_19695_2017_EN.pdf?ua=1). 